\title{
Epidemiology and burden of rotavirus diarrhea in day care centers in Lyon, France
}

\author{
Daniel Floret • Bruno Lina • Sybil Pinchinat • \\ Geneviève Billaud • Fatima Aït-Belghiti • \\ Nathalie Largeron - Béatrice Bellemin • \\ Cao Nong Trang • Catherine Fau • Claude Gaspard • \\ Valérie Mamoux $\cdot$ Lydie Marcelon
}

Published online: 3 October 2007
(C) Springer-Verlag 2007

\section{Eur J Pediatr (2006) 165:905-906}

The following text should replace paragraphs 4 to 10 in the original publication. Reference 4 has been modified. Table 1 and Fig. 1 are also modifed.

The online version of the original article can be found at http://dx.doi. org/10.1007/s00431-006-0187-z.

\author{
S. Pinchinat $(\bowtie)$ \\ Biostatem, \\ 176 Avenue de la Royale, \\ 34160 Castries, France \\ e-mail: sybil.pinchinat@biostatem.com \\ D. Floret \\ Service d'Urgence et de Réanimation Pédiatriques, \\ Hôpital Edouard Herriot, \\ 1 place d'Arsonval, \\ 69437 Lyon, France \\ B. Lina $\cdot$ G. Billaud \\ Laboratoire de Virologie, Faculté de médecine \\ Lyon Grange Blanche, Domaine universitaire Rockefeller, \\ 8 avenue Rockefeller, \\ 69373 Lyon Cedex 08, France \\ F. Aït-Belghiti $\cdot$ N. Largeron $\cdot$ L. Marcelon \\ Sanofi Pasteur MSD Europe, \\ 8 rue Jonas Salk, \\ 69367 Lyon Cedex 07, France \\ B. Bellemin $\cdot$ C. N. Trang $\cdot$ C. Fau $\cdot$ C. Gaspard • V. Mamoux \\ Council DCCs referent physicians, \\ Lyon, France
}

Sixty-three AGE cases occurred in 54 children ( 9 children had two episodes of gastroenteritis). Twenty-nine AGE cases (46\%) tested positive for rotavirus (PRGE) and 34 (54\%) were non-rotavirus (non-PRGE). Children with PRGE were significantly younger than those with nonPRGE $(p<0.05)$.

Among PRGE cases, 11 were male, 18 were breast-fed and the median age was 12.1 months. The incidence of PRGE cases was estimated at 0.026 per child-months over the study period, increasing to 0.034 per child-months among children less than 2 years of age.

The first case of PRGE occurred in December and the peak of PRGE was observed in January 2005 (Fig. 1). Out of 63 AGE cases, 58 gastroenteritis questionnaires were filled by parents. Vomiting and behavior modification were significantly more current for PRGE cases. The PRGE cases were significantly more severe than non-PRGE cases (Table 1).

Ten of PRGE cases infected $\geq 1$ household member, and 24 PRGE cases sought medical care (visit or phone call to general practitioner, pediatrician or emergency unit). For 14 of these PRGE cases, at least one parent had to miss work for a mean of 2.1 days. The total cost of PRGE cases seeking medical attention was estimated at $275 € /$ case: $23.5 \%$ were direct costs and $76.5 \%$ were indirect costs.

The PRGE incidence ( 0.022 child-months) is similar to that estimated in other DCC studies: 0.011 childmonths by Ford-Jones et al. (2) and 0.029 child-months by Hjelt et al. (3). In this study, the PRGE cases were significantly more severe. This is consistent with findings from a recent and large epidemiological study that 


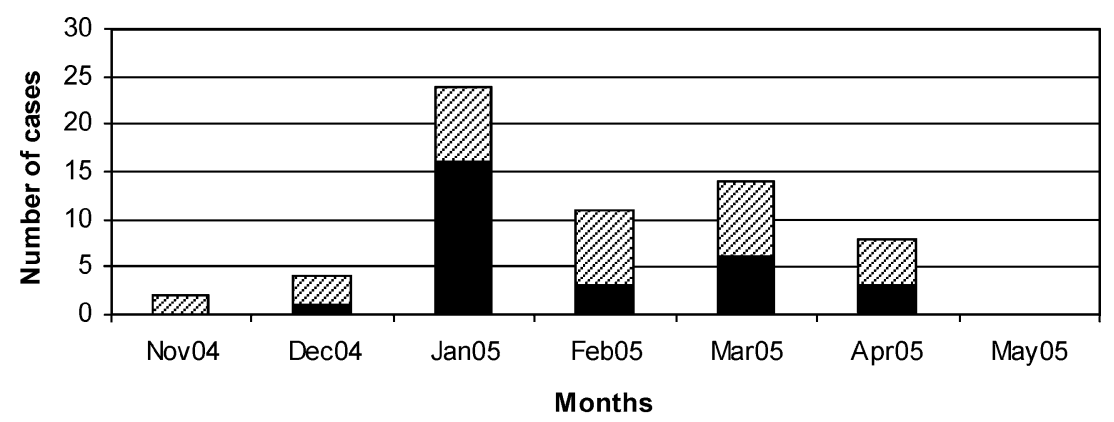

PRGE a Non-PRGE

Fig. 1 Distribution per month of pediatric rotavirus gastroenteritis (PRGE) and non-PRGE cases

Table 1 Clinical and management characteristics of PRGE and non-PRGE cases

\begin{tabular}{|c|c|c|c|c|}
\hline \multicolumn{2}{|l|}{ Variable analysed } & \multirow{2}{*}{$\begin{array}{l}\text { PRGE }(N=28) \\
28\end{array}$} & \multirow{2}{*}{$\frac{\text { Non-PRGE }(N=30)}{26}$} & \multirow{2}{*}{$\frac{\text { Tests }}{\mathrm{NS}^{\mathrm{a}}}$} \\
\hline Diarrhea & $n$ & & & \\
\hline Duration of diarrhea (days) & median $(\min -\max )$ & $5(1-10)$ & $3(1-16)$ & $\mathrm{NS}^{\mathrm{b}}$ \\
\hline Vomiting & $n$ & 23 & 11 & $\mathrm{p}=0.0004^{\mathrm{c}}$ \\
\hline Duration of vomiting (days) & median $(\min -\max )$ & $2(1-8)$ & $2(1-4)$ & $\mathrm{NS}^{\mathrm{b}}$ \\
\hline Fever & $n$ & 19 & 13 & $\mathrm{NS}^{\mathrm{c}}$ \\
\hline Duration of fever (days) & median $(\min -\max )$ & $2(1-9)$ & $2(1-6)$ & $\mathrm{NS}^{\mathrm{b}}$ \\
\hline Behavior modification & $n$ & 27 & 18 & $\mathrm{p}=0.0009^{\mathrm{c}}$ \\
\hline Duration of behavior modification (days) & median (min - max) & $3(1-8)$ & $2(1-8)$ & $\mathrm{NS}^{\mathrm{b}}$ \\
\hline Severity score & median $(\min -\max )$ & $12.5(4-21)$ & $6(0-18)$ & $\mathrm{p}=0.0001^{\mathrm{b}}$ \\
\hline Medical case & $n$ & 24 & 14 & $\mathrm{p}=0.0018^{\mathrm{c}}$ \\
\hline
\end{tabular}

${ }^{a}$ Fisher test

${ }^{\mathrm{b}}$ Wilcoxon test

${ }^{\mathrm{c}} \mathrm{Chi}^{2}$ test

showed rotavirus-positive AGE cases to have more severe disease than rotavirus-negative AGE (4). The cost estimate for a PRGE case (275€) in France is close to the cost reported in two studies conducted in the UK $(240 €$ and $255 €)(5,6)$.

\section{References}

4. Giaquinto C, Van Damme P, Huet F, Gothefors L, Maxwell M, Todd P, Da Dalt L (2007) Clinical consequences of rotavirus acute gastroenteritis in Europe, 2004-2005: the REVEAL study. J Infect Dis 195:S26-S35 